\title{
Review of: "Phenotypic plasticity in adults of Anticarsia gemmatalis exposed to sub-doses of Bt- based bioinsecticide"
}

\author{
María Inés Herrero
}

Potential competing interests: The author(s) declared that no potential competing interests exist.

This article aims to evaluate the effects on A. gemmatalis morphometry of Bt-based bioinsecticide Dipel SC over the three generations under laboratory conditions. For this, the authors measure and weight different body segments in adult males and females over three generations. In general, I think that they provide valuable information, considering that there are no previous studies about phenotypic plasticity in adults of A. gemmatalis. However, I think that the title "Phenotypic plasticity" could be excessive, considering that the term "Phenotypic" not only implies morphometry.

I found the results a little difficult to follow. I would include only those values with significant differences; the rest can be read and interpreted from the tables.

Also, there are grammatic/typing errors that can be corrected. For example: Is "Hübner", instead of "Hünber". Is "measured" instead of "mensuread". Also, the authors sometimes use the abbreviation "CL" and other times "LC" to indicate "Lethal concentration". They need to uniform this.

In the discussion, I think that is ok, considering that they emphasize the importance of the morphometric parametres measured and the impact that they have on biology and reproduction of this species. However, I think that this could be more comprehensive if they include and discuss the specific results obtained in this research. In some paragraphs, they do it, but I think that it needs more discussion comparing results of other related species (considering that there are no other studies about A. gemmatalis adults morphometry). 